\begin{tabular}{|l|l|l||}
\hline \multicolumn{2}{|c|}{ PublisherInfo } \\
\hline \hline PublisherName & $:$ & BioMed Central \\
\hline \hline PublisherLocation & $:$ & London \\
\hline \hline PublisherImprintName & $:$ & BioMed Central \\
\hline \hline
\end{tabular}

\title{
Replacement of the aortic root in patients with Marfan's syndrome
}

\begin{tabular}{|l|l|l||}
\hline \multicolumn{2}{|c||}{ ArticleInfo } \\
\hline \hline ArticleID & $:$ & 4108 \\
\hline \hline ArticleDOI & $:$ & $10.1186 /$ ccf-1999-265 \\
\hline \hline ArticleCitationID & $:$ & 265 \\
\hline \hline ArticleSequenceNumber & $:$ & 45 \\
\hline \hline ArticleCategory & $:$ & Paper Report \\
\hline \hline ArticleFirstPage & $:$ & 1 \\
\hline \hline ArticleLastPage & $:$ & 4 \\
\hline \hline & & RegistrationDate : 1999-5-13 \\
\hline ArticleHistory & $:$ & OnlineDate \\
\hline \hline ArticleCopyright & $:$ & Current Science Ltd1999-5-13 \\
\hline \hline ArticleGrants & $:$ & \\
\hline \hline ArticleContext & $:$ & 130541111 \\
\hline \hline
\end{tabular}




\section{Keywords}

\section{Comments}

These results are retrospective and of a predominantly North Americanexperience but do constitute a large number over a long period of time.Several interesting points are raised. The mortality from replacement with a homograft washigher, but this is a newer and more complex procedure and may reflect alearning curve. This group would also not require anticoagulants and $2 \%$ of late mortality was from warfarin induced hemorrhage.

\section{Introduction}

Marfan's syndrome involves the skeletal, ocular and cardiovascular systems and may lead to premature death, usually from thoracic rupture. The syndrome was first described in 1896 but association with aneurisms of the ascending aorta was not described until much later (1943). Recent improvements in the investigation of these patients, eg with transesophageal echocardiography, enables proactive treatment of large or rapidly enlarging aneurisms. Several surgical strategies for repair of these aneurisms have been described, most commonly a composite graft-valve with reanastomosis of the coronary arteries on to the graft (Bentall procedure), although homografts have recently been used (which prevent the need for long term anticoagulation).

\section{Aims}

This study collected the data from 10 surgical centers to evaluate outcome and timing of surgical intervention.

\section{Methods}


Data were obtained from seven North American and three European centers and the records of 675 patients were analysed. Patients were only included if they had a definite diagnosis of Marfan's syndrome. Follow-up data were obtained for $91 \%$ of patients with a mean follow up of 6.7 years (ranges 0-23). Six hundred and four patients underwent Bentall procedures, 21 homograft root replacements, and 50 valve sparing surgery.

\section{Results}

Two hundred and two patients had aortic dissections and 99 of these were acute and operated on within 14 days. The mean aortic diameter was marginally larger for those with dissection 7.2 versus 6.8 $\mathrm{cm}$ but $46 \%$ of patients with dissection had a diameter of $6.5 \mathrm{~cm}$ or less.

The 30 day operative mortality was low; $1.5 \%$ for elective repairs, $2.6 \%$ for urgent repairs (within 7 days of initial consultation) and $11.7 \%$ for emergency repairs. Indication for emergency surgery included dissection, chest pain, an aneurism larger than $7 \mathrm{~cm}$ and New York Health Association grade III or IV heart failure. Mortality at 30 days was highest for those receiving homograft replacement (4.8\%), 3.5\% for composite grafts and $0 \%$ for valve sparing surgery, although there was a large overlap of confidence intervals. Late survival rates were $93 \%$ at 1 year, $91 \%$ at 2 years, $84 \%$ at 5 years, $75 \%$ at 10 years and $59 \%$ at 20 years. Late deaths were from a variety of causes; 22 resulted from dissection or rupture of the residual aorta, two from warfarin induced hemorrhage, and endocarditis occurred in 24 patients causing late death in 10 patients.

\section{Discussion}

The most important finding is that the elective mortality is very low and on a par with less complex aortic surgery (aortic valve replacement); this has undoubtedly dramatically improved the life expectancy of patients with Marfan's syndrome (from 45 years in 1972 to 72 years in 1995). A large number of patients presenting with acute dissections had aneurisms of $6.5 \mathrm{~cm}$ or less suggesting that $5.5-6 \mathrm{~cm}$ is the right diameter at which to perform elective operation. Endocarditis is a significant problem and the authors recommend parenteral rather than oral antibiotics for patients, with valve composite grafts undergoing dental procedures. Late rupture of the residual aorta is a relatively frequent cause of death and emphasises the need for these patients to be followed up with imaging of the aorta and administration of beta blockade to reducehemodynamic stress.

\section{Additional information}

An editorial accompanies this article ( $N$ Engl J Med 1999, 340:1358-1359). 


\section{References}

1. Gott VL, Greene PS, Alejo DE, Cameron DE, Naftel DC, Miller C, Gillinov AM, Lashinger JC, Pyeritz RE: Replacement of the aortic root in patients with Marfan's syndrome. N Engl J Med. 1999, 340: 1307-1313.

This PDF file was created after publication. 